\title{
REPRESENTATIVIDADE E PARTICIPAÇÃO DIANTE DO ESTADO CAPITALISTA MODERNO E A GOVERNABILIDADE DEMOCRÁTICA
}

\section{Rodrigo de Camargo Cavalcanti}

Autor correspondente. Centro Universitário Alves Faria - Unialfa. Av. Perimetral Norte, 4129 - St. Vila João Vaz. Goiânia/GO, Brasil. CEP 74445-190. http://lattes.cnpq.br/0666558204580403. https://orcid.org/0000-0001-8633-4922. rodrigoccavalcanti@gmail.com

\section{Thiago Lopes Matsushita}

Pontifícia Universidade Católica de São Paulo. São Paulo/SP, Brasil.

\section{RESUMO}

O presente artigo objetiva analisar a democracia representativa diante da proposta da democracia direta e participativa no contexto do Estado moderno e contemporâneo capitalista. Segue a metodologia dedutiva, com pesquisa em obras e legislações atinentes ao tema. Primeiramente apresenta sucinto escorço histórico sobre a fundação da sociedade de classes e do Estado. Em seguida analisa a democracia representativa como principal modelo do Estado moderno. Posteriormente, coteja a tese da ingovernabilidade, conforme discorrida por Norberto Bobbio, da democracia direta e participativa. Por fim, conclui pela necessária e urgente inclusão da sociedade civil na participação direta das decisões políticas.

Palavras-chave: Estado; democracia; capitalismo; participação.

\section{REPRESENTATIVENESS AND PARTICIPATION IN FACE OF THE MODERN CAPITALIST STATE AND DEMOCRATIC GOVERNABILITY}

\section{ABSTRACT}

This article aims to analyze representative democracy in the face of the proposal of direct and participatory democracy in the context of the modern and contemporary capitalist state. It follows the deductive methodology, with research in works and legislation related to the subject. First, it presents a brief historical overview of the foundation of class society and the State. Then it analyzes representative democracy as the main model of the modern state. Later, it compares the ungovernability thesis, as discussed by Norberto Bobbio, of direct and participatory democracy. Finally, it concludes for the necessary and urgent inclusion of civil society in the direct participation of political decisions.

Keywords: State; democracy; capitalism; participation.

Financiamento: Fundação Nacional de Desenvolvimento do Ensino Superior Particular (Funadesp).

Recebido em: 23/7/2021

Aceito em: 26/10/2021 


\section{INTRODUÇÃO}

As bases da composição social, econômica e política de uma determinada sociedade, constituídas por tecnologias de adaptação de seus membros, tanto individualmente quanto em seu coletivo, são condições cuja análise não se pode deixar de lado se a intenção for compreender integralmente as suas dinâmicas relacionais e a sua estrutura.

Ao incorporar premissas da investigação por uma abordagem holística e sistêmica, essa forma de análise permite identificar os modelos, as ideologias e os padrões que orientam as instituições sociais, assim como alternativas possíveis e necessárias para a consolidação efetiva de princípios e enunciados construídos objetivando a ampla garantia da dignidade humana.

Assim, este trabalho, por meio de metodologia dedutiva com pesquisa bibliográfica e legislativa, coteja resumidamente a concepção do Estado moderno em suas origens mais radicais, ou seja, a partir do surgimento social das relações de sujeição e poder e hierarquia de classes, o que se dá primordialmente com a revolução do neolítico - conforme indica Peter Joseph - e com o surgimento posterior do Estado - mais salientado ainda por Pierre Clastres. Em seguida, analisa o aporte democrático, representativo e participativo, do Estado moderno e contemporâneo.

\section{BREVES CONSIDERAÇÕES HISTÓRICAS}

A fase pré-neolítica é majoritariamente caracterizada pelo nomadismo, tipo de vida específico dos denominados caçadores-coletores, tendo em vista a incipiente utilização da agricultura. Não se afirma aqui que só havia nômades anteriormente à revolução neolítica. $A$ possibilidade de formação do sedentarismo e da agricultura antes mesmo de tal momento é defendida por alguns autores, como Pierre Clastres.

Clastres inclusive sustenta a possibilidade nada remota da existência de caçadores-coletores também, mesmo sem a tecnologia da agricultura, adaptados ao sedentarismo.

A relevância dessa assertiva encontra-se no momento em que o pesquisador Peter Joseph expõe o neolítico paralelamente ao aumento da sociedade sedentária, e esse aspecto como central para a emergência de divisões socioeconômicas no interior das comunidades de então. Em seus termos:

Desde a Revolução Neolítica, tivemos um processo de adaptação cultural impulsionado economicamente, construído em torno dos requisitos de sobrevivência do paradigma agrário relativamente novo estabelecido. Essa evolução da cultura pós-neolítica foi autoguiada por pressões ambientais sistêmicas e inferências na sobrevivência comuns à dinâmica natural do novo modo de produção. Isso deu origem a incentivos de dominação, valores e proteções envolvendo padrões de conflito, hierarquia e alocação desproporcional de recursos físicos e sociais. Com o tempo, esses incentivos, valores e proteções passaram a ser aceitos como "é assim que é" e o que a maioria considera "normalidade" hoje é o que tem sido resultado ${ }^{1}$ (JOSEPH, 2017, tradução nossa).

\footnotetext{
"Since the Neolithic Revolution, we've had a process of economically driven cultural adaptation built around the survival requisites of the relatively new, settled agrarian paradigm. This evolution of post-Neolithic culture was self-guided by systemic environmental pressures and survival inferences common to the natural dynamics of the new mode of production. This gave birth to dominance-oriented incentives, values, and protections, evolving patterns of conflict, hierarchy, and disproportional allocation of physical and social resources. Over time, these incentives, values, and protections became accepted as 'just the way it is' and what most consider 'normality' today has been the result."
} 
Desse modo, citando Robert Sapolsky, para Joseph (2017): os "caçadores-coletores tinham milhares de recursos na natureza de alimento para sobreviverem" ${ }^{2}$. Com a ampliação do uso da agricultura e, então, do sedentarismo, "o armazenamento de recursos excedentes e, inevitavelmente, o armazenamento desigual", ${ }^{3}$ levou à "estratificação da sociedade e à invenção das classes", ${ }^{4}$ culminando no surgimento da pobreza. Conclui, assim, que

[...] serve para dar uma ideia de como a introdução de novos meios de sobrevivência pode criar trajetórias complexas e mesmo negativas à medida que a evolução social avança. Na verdade, como definimos o próprio progresso na sociedade torna-se igualmente complexo, pois o que pode parecer um passo lógico na direção certa em determinado momento pode muito bem se revelar problemático de certas maneiras com o passar do tempo ${ }^{5}$ (JOSEPH, 2017, tradução nossa).

Percebe-se, assim, que Peter Joseph enfoca o surgimento da distinção entre classes a partir do viés econômico incorporado à revolução neolítica. Pierre Clastres, por sua vez, mesmo compreendendo a importância desse processo, para a caracterização do que entendemos hoje por sociedade, e direitos como o de propriedade, atualmente considerados como intrínsecos ao ser humano, parte do surgimento do poder como um divisor de águas substancialmente importante para a configuração do que viria a ser o Estado, ou seja, sua hipótese é política. Em seus termos:

A verdadeira revolução, na proto-história da humanidade, não é a do neolítico, uma vez que ela pode muito bem deixar intacta a antiga organização social, mas a revolução política: é essa aparição misteriosa, irreversível, mortal para as sociedades primitivas, que conhecemos sob o nome de Estado. E caso haja desejo de conservar os conceitos marxistas de infraestrutura e de superestrutura, então talvez seja necessário reconhecer que a infraestrutura é o político e que a superestrutura é o econômico. Somente uma convulsão estrutural, abissal pode transformar, destruindo-a como tal, a sociedade primitiva: aquilo que faz surgir em seu seio, ou do exterior, aquilo cuja ausência mesma define essa sociedade, a autoridade da hierarquia, a relação de poder, a dominação dos homens, o Estado (CLASTRES, 1974, p. 14).

Isso posto, vale salientar que, mesmo partindo de pontos de vistas relativamente diversos, ambos os autores realizam suas investigações tendo como ponto de partida a revolução neolítica e o surgimento do Estado. O ponto histórico que une a doutrina de ambos orienta-se igualmente à crítica do Estado como instituição perpetuadora do domínio de poucos sobre muitos.

O Estado, então, na doutrina dos autores, confere forma e conteúdo para, assim, garantir-se como instrumento da nobreza, da burguesia e posteriormente dos donos dos meios de produção e investidores financeiros, para a sustentação ideológica de premissas que satisfazem a manutenção do status quo e de poucos privilégios intrínsecos e historicamente transmitidos.

\footnotetext{
"Hunter-gatherers [had] thousands of wild sources of food to subsist on".

"the stockpiling of surplus resources and thus, inevitably, the unequal stockpiling of them."

"stratification of society and the invention of classes."

"it serves to give a sense of how the introduction of new means for survival can create complex and even negative trajectories as social evolution plows forward. In fact, how we define progress itself in society becomes equally complex, for what may seem like a logical step in the right direction at one time may very well prove problematic in certain ways as time goes on".
} 


\section{O ESTADO MODERNO E A DEMOCRACIA REPRESENTATIVA}

A Revolução Francesa, na condição de marco do Estado moderno, colabora para a ampliação de outras soberanias de propostas constitucionais de nação, da ainda incipiente formação do instituto da democracia, majoritariamente representativa, e dos direitos humanos, ainda que restritos à legitimação e enunciação positiva das liberdades formais.

Ademais, desde a Constituição Americana de 1787 já se alinhava a intenção do que viria posteriormente a se efetivar como o viés da proposta democrática de então. Condizente às bases do modelo aristocrático europeu, James Madison, conhecido como o pai da Constituição Americana, explicou, na Convenção Federal de 1787, porque o Senado deveria ser criado: "eles devem ser constituídos de forma a proteger a minoria dos opulentos contra a maioria. O Senado, portanto, deve ser este corpo; e para atender a esses propósitos, eles devem ter permanência e estabilidade" ${ }^{\prime 6}$ (UNITED, 1911, v. 1, p. 431).

Assim como os direitos humanos, ainda incipientes, foram institucionalizados basicamente mediante as liberdades formais, inserido nelas o sufrágio universal, a proposta de materialidade da democratização do poder estatal foi inaugurada e ampliada para a maior parte do mundo limitada ao sistema representativo.

Dito modelo, formalmente indicando uma restrição à participação popular, com raras possibilidades de intervenção que não pelo voto, se cristalizou de fato como um quase contraponto à democracia direta ou participativa.

Diz-se isso pois a interferência dos donos dos meios de produção, desde a Revolução Industrial, posteriormente dos seus herdeiros e investidores partícipes do sistema financeiro, sobre as instituições estatais e seu aparato burocrático, consolidou-se como condição inerente a esse sistema.

A limitação da democracia representativa, então, reside no fato de não ser na prática uma forma de poder delegada pelo povo, mas sim, ao contrário, uma "forma de poder exercida por políticos profissionais e funcionários públicos sobre o povo, em que alguns desses governantes são periodicamente trocados pelo mecanismo de eleição" (HIRST, 1993, p. 36).

Dessa maneira, mediante a possibilidade de investimentos privados em campanhas, reuniões fechadas, persuasão, favores, e em virtude da relação intrínseca entre o mercado capitalista e o desenvolvimento de tecnologias, bens de consumo e serviços, o Estado, na condição de órgão legislativo, fiscalizador, sancionador e detentor do poder de violência, fica submetido aos interesses de poucos com altíssimo poder financeiro de barganha. Então, o controle privado é garantido por meio "de um aumento na influência sobre os governos, como uma maneira de salvaguardar seu poder, mediante lobbying, contribuições políticas, revolving door mechanisms ${ }^{7}$ (teoria da captura), etc." (CAVALCANTI, 2016, p. 339). Assim, "maior con-

\footnotetext{
6 "They ought to be so constituted as to protect the minority of the opulent against the majority. The Senate, therefore, ought to be this body; and to answer these purposes, they ought to have permanency and stability."

7 "Revolving door mechanisms" são movimentos de pessoal entre funções como legisladores e/ou reguladores e funções nas indústrias afetadas pela mesma legislação e/ou regulamentação.
} 
trole sobre o governo significa que os regulamentos, leis e instituições devem ser amplamente alinhados com, e subservientes aos interesses dos oligopólios" ${ }^{8}$ (SUAREZ-VILLA, 2015, p. 203).

Diante dessa realidade, a fragilidade institucional da democracia representativa é patente. A crise do subprime de 2008 foi um grande exemplo da cooptação do governo estadunidense com as instituições financeiras diante da introdução da prática das corporações "too big to fail". Nesse momento, as teorias neoliberais que tendiam ao purismo de seus termos tomando como referência os EUA tiveram de repensar seus conceitos. Alan Greenspan, ex-presidente do Federal Reserve, em audiência:

[...] admitiu pela primeira vez ter errado, ainda que 'parcialmente', ao se opor a uma maior regulamentação de derivativos e regulação de bancos enquanto estava à frente do Fed, e frisou que as instituições financeiras não protegeram os investidores e aplicações tão bem quanto ele previa.

- Sim, encontrei uma falha - disse Greenspan, ao responder a uma sessão de perguntas da Comissão de Supervisão e Reforma Governamental da Câmara. - É exatamente por isso que fiquei chocado, pois acompanhei 40 anos ou mais de evidências bastante significativas de que (o modelo baseado nessa ideologia) estava funcionando excepcionalmente bem (O GLOBO, 2008, p. 32).

Não há como objetar que a ordem econômica capitalista caminha pari passu com a democracia representativa, principalmente diante das propostas e resoluções governamentais diante das crises econômicas mais recentes e de alcance global que nada mais são do que expressões em maior escala da influência de grandes corporações oligopolistas e instituições de forte influência sobre as decisões políticas de impacto social não raramente indeléveis.

Assim, uma questão que emerge é sobre qual é a possibilidade futura de instituição de uma governança democrática do poder público verdadeiramente instituída, orientada e legitimada pela sociedade civil, a fim de não lhe escapar a necessária empreitada em prol da garantia de seus direitos mais fundamentais.

\section{DEMOCRACIA DIRETA E PARTICIPATIVA E A TESE DA INGOVERNABILIDADE}

Muitas vezes, ao se falar de democracia participativa e direta, tem-se o retorno à análise do governo de Atenas. Ainda que ciente desse importante cotejo, vale salientar que a sociedade complexa contemporânea requer demandas igualmente complexas, muito diversas daquelas que orientavam a política da Grécia antiga.

Diante de tal complexidade atual, algumas dificuldades são apresentadas, como aquelas que aqui se englobam sob a "tese da ingovernabilidade".

Tal tese diz respeito à construção argumentativa realizada por Norberto Bobbio no último capítulo de sua obra "Liberalismo e democracia", de 1985, com a 1a edição brasileira em 1988.

\footnotetext{
8 "Greater control over government means that regulations, laws, and institutions must be largely aligned with, and subservient to, the interests of the oligopolies.
} 
Nesse capítulo, "Democracia e ingovernabilidade", Bobbio elenca três principais argumentos aos quais os regimes democráticos estariam predestinados, que fundamentariam tal ingovernabilidade.

O primeiro diz respeito a um fenômeno denominado pela teoria dos sistemas de "sobrecarga". Tal sobrecarga estaria presente por conta de duas razões principais: (a) o funcionamento adequado do poder popular pressupõe que estejam amplamente garantidas as liberdades sindicais, partidária, de reunião, associação, ou seja, grande extensão dos direitos políticos, abrindo o caminho para facilitar o encaminhamento de demandas da sociedade civil para o poder público, condicionando a este a garantia de respostas da forma mais célere possível, a fim de garantir a eficácia e o consenso sobre as respectivas matérias; e (b) a descentralização das demandas e das decisões podem desacelerar e esvaziar tal compromisso democrático assumido, "através do jogo dos vetos cruzados" (BOBBIO, 2007, p. 93).

No segundo tópico Bobbio expõe que, com o aumento da liberdade associativa, aumenta-se necessariamente a quantidade de conflitos sociais existentes, e então "mais se aumenta a dificuldade de dominá-los" (p. 93). "Numa sociedade pluralista, como é a que vive e floresce num sistema político democrático, onde o conflito de classe é multiplicado por uma miríade de conflitos menores corporativos, os interesses contrapostos são múltiplos" (p. 93), levando à incapacidade de corresponder positivamente a um sem ofender outro. Dessa maneira, ainda os únicos interesses comuns geralmente satisfeitos num governo democrático são aqueles "que produzem maiores consensos e são sempre interesses parciais" (p. 94).

Por fim, o terceiro ponto que revelaria dita ingovernabilidade é uma difusão e fragmentação do poder a ponto de ser de difícil recomposição. Essa situação leva a uma concorrência entre os próprios poderes responsáveis por resolver os conflitos, tornando patológica a normal conflitualidade social.

Bobbio de fato não cede críticas a tais pontos, mas traz assertiva relevante no final do texto ao afirmar a necessidade de uma relação imbricada entre democracia e liberalismo. Afirma isso ao expor a tese da necessária suspensão de alguns direitos como inalienáveis, característica essa que os posiciona acima dos debates democráticos, mesmo em democracias diretas ou participativas.

Sustentando essas palavras de Bobbio, cabe especificar que, se assim não for, corre-se o risco de estarem prejudicadas as próprias liberdades que o Estado Democrático se propôs a garantir, seja enquanto enunciados à dignidade ou mesmo simplesmente como instrumentos jurídicos de defesa em prol da garantia de livre e autônoma expressão nesse contexto social participativo.

Há amplo debate sobre tais argumentos levantados por aqueles que salientam uma possível ingovernabilidade em propostas de democracia direta e participativa.

Há no Brasil alguns casos concretos de instituição de programas de participação popular. Um deles é o Orçamento Participativo da cidade de Porto Alegre, elencado pela ONU como uma "das 40 melhores práticas de gestão pública urbana no mundo" (PREFEITURA, 2020), e pelo Banco Mundial "como exemplo bem-sucedido de ação comum entre governo e sociedade civil" (PREFEITURA, 2020), funcionando, em linhas gerais, da seguinte maneira: 


\section{Democracia}

O Ciclo do OP se caracteriza por três grandes momentos prioritários: as reuniões preparatórias, a Rodada Única de Assembleias Regionais e Temáticas e a Assembleia Municipal. Inicia-se com as reuniões preparatórias, quando a Prefeitura presta contas do exercício passado, apresenta o Plano de Investimentos e Serviços (PIS) para o ano seguinte.

As secretarias municipais e autarquias acompanham estas reuniões, prestando esclarecimentos sobre os critérios que norteiam o processo e a viabilidade das demandas.

Nas Assembleias Regionais e Temáticas, nas 17 Regiões e seis Temáticas do OP, a população elege as prioridades para o município, seus conselheiros e define o número de delegados da cidade, para os seus respectivos fóruns regionais e grupos de discussões temáticas.

Os Fóruns de Delegados são responsáveis pela definição, por ordem de importância, das obras e serviços que serão discutidas nas regiões e temáticas (PREFEITURA, 2020).

Vale também citarmos a Lei 8.142/1990, que, entre outras matérias, dispõe sobre a participação da sociedade na gestão do Sistema Único de Saúde (SUS). Com essa intenção, enuncia a criação do Conselho de Saúde, órgão colegiado composto por representantes do governo, prestadores de serviço, profissionais de saúde e usuários, atuante na formulação de estratégias e no controle da execução da política de saúde na instância correspondente, inclusive nos aspectos econômicos e financeiros (artigo 1으, §2 $2^{\circ}$ ); e da Conferência de Saúde, de reunião periódica e com a representação dos vários segmentos sociais, para avaliar a situação de saúde e propor as diretrizes para a formulação da política de saúde nos níveis correspondentes (artigo $1^{\circ}, \S 1^{\circ}$ ).

Outro exemplo relevante é o Projeto de Lei 4.718/2004, apresentado à Câmara dos Deputados pelo Conselho Federal da Ordem dos Advogados do Brasil, com redação do jurista Fábio Konder Comparato. Esse PL tem por objetivo regulamentar o artigo 14 da Constituição, em matéria de plebiscito, referendo e iniciativa popular. Enuncia que o povo decidirá em plebiscito e de forma soberana: sobre a criação, a incorporação, a fusão e o desmembramento de Estados ou municípios, bem como a criação de Territórios Federais, a sua transformação em Estado ou reintegração ao Estado de origem (I); a execução de serviços públicos e programas de ação governamental, nas matérias de ordem econômica e financeira, bem como de ordem social, reguladas nos Títulos VII e VIII da Constituição Federal (II); e a concessão administrativa de serviços públicos, em qualquer de suas modalidades, bem como a alienação de controle de empresas estatais (III).

Atualmente esse PL encontra-se apensado ao Projeto de Lei 6.928/2002, de mesma matéria e formulado com a proposta de criar o "Estatuto para o exercício da Democracia Participativa", regulamentando a execução do disposto nos incisos I, II e II, igualmente do referido artigo 14 da Constituição.

\section{CONCLUSÃO}

O debate sobre a historicidade da fundação da sociedade de classes é muito bem representado pelos trabalhos de Peter Joseph e Pierre Clastres. O primeiro enfatizando a transição do pré para o pós-neolítico e seu aspecto econômico principalmente criado pelo surplus por conta do sedentarismo, da efetiva consolidação do modelo agrícola e da consequente possibilidade de armazenamento e diversificação variada, conforme a disposição geográfica e da técnica, de alimentos; enquanto o segundo argumenta pela relevância do aspecto político do 


\section{Democracia}

poder como premente para o surgimento da instituição estatal. Ambos, dessa forma, conduzem suas teorias para a crítica do Estado como instituição orientada à manutenção da hierarquia de classes.

Posteriormente, com a institucionalização na modernidade de um Estado marcado pelo modelo representativo de democracia, a absorção das instituições estatais pelos mais abonados é cenário muito bem conhecido da História, instaurado e permanente na atualidade, podendo ser observado como situação que se estabelece globalmente e com efeitos muitas vezes gravosos à sociedade civil e seus mais caros direitos.

Da mesma maneira, diante da complexidade social contemporânea, algumas dificuldades em contornar tal processo mediante a instauração de democracias mais participativas são dispostas na doutrina. Ainda assim, no Brasil, por exemplo, é possível observar alguns modelos e projetos em torno da institucionalização de uma maior participação da sociedade civil nas decisões do poder público. Insta salientar, por fim, a permanente busca na consolidação de propostas que estejam orientadas a abarcar os interesses mais prementes para a consolidação da dignidade em nível integral e universalizada, com a expressão e voz cada vez mais ativas pela parte mais interessada do processo político democrático.

\section{REFERÊNCIAS}

BOBBIO, N. Liberalismo e democracia. São Paulo: Editora Braziliense, 2007.

CAVALCANTI, R. de C. Reprodução e comoditização: dualidade no ambiente oligopolista. Revista do Curso de Mestrado em Direito da Universidade Católica de Brasília, Brasília, v. 10.2, n. 2, p. 330-354, jul./dez. 2016.

CLASTRES, P. A sociedade contra o Estado. 1974. Disponível em: https://we.riseup.net/assets/71282/clastres-a-sociedade-contra-o-estado.pdf. Acesso em: 23 jul. 2021.

HIRST, P. A democracia representativa e seus limites. Rio de Janeiro: Jorge Zahar Editor, 1993.

JOSEPH, P. The New Human Rights Movement. Reinventing the economy to end oppression. Kindle Edition. Dallas: BenBella Books, 2017.

O GLOBO. Greenspan, pela primeira vez, admite que errou. 2008. Disponível em: https://www2.senado.leg.br/ bdsf/bitstream/handle/id/408421/noticia.htm?sequence=1. Acesso em: 23 jul. 2021.

PREFEITURA de Porto Alegre. OP, 25 anos em Porto Alegre. 2020. Disponível em: http://www2.portoalegre.rs. gov.br/smgl/default.php?p_secao=86. Acesso em: 23 jul. 2021.

SUAREZ-VILLA, L. Corporate power, oligopolies and the crisis of the state. New York: State University of New York Press, 2015.

UNITED STATES CONSTITUTIONAL CONVENTION. The Records of the Federal Convention of 1787. Connecticut: Yale University Press, 1911. 